\title{
Thermodynamics limits the reactivity of BrHg• radical with volatile organic compounds
}

\author{
Theodore S. Dibble* and Abraham C. Schwid
}

Chemistry Department, SUNY-Environmental Science and Forestry, Syracuse, NY 13210 USA

\begin{abstract}
$\underline{\text { Abstract }}$
Mercury emissions to the atmosphere primarily consist of $\operatorname{Hg}(0)$, which tends not to enter ecosystems until it is oxidized. Atomic bromine initiates oxidation of $\mathrm{Hg}(0)$ via the $\mathrm{BrHg} \bullet$ intermediate, but the further reactions of $\mathrm{BrHg} \bullet$ are just beginning to be explored. Here we use quantum chemistry to determine that hydrogen abstraction from hydrocarbons by BrHg• is so endothermic as to be irrelevant. Bonds between $\mathrm{BrHg} \bullet$ and carbon atoms are so weak that $\mathrm{BrHg} \bullet$ addition to carbon-carbon double bonds atoms will be somewhat ineffective in leading to further reactions.
\end{abstract}

Keywords: atmospheric chemistry, reactive gaseous mercury, kinetics, radicals

* FAX: 315-470-6856, tsdibble@esf.edu 


\section{Introduction}

Mercury is a neurotoxin. The atmosphere acts as a highway to transport mercury around the globe. ${ }^{1,2}$ Mercury is emitted to the atmosphere primarily as gaseous elemental mercury $(\operatorname{Hg}(0)) .^{3}$ Due to its relatively high equilibrium vapor pressure and low water solubility, gaseous $\operatorname{Hg}(0)$ is only very slowly deposited to the Earth's surface. ${ }^{1}$ By contrast, gaseous oxidized mercury (GOM) compounds have much lower vapor pressures and higher water solubility, and are much more efficiently transferred from the atmosphere to soil and water. Upon entering ecosystems, oxidized mercury can be transformed into organomercury compounds, which bioaccumulate as one rises up the food chain. ${ }^{4}$ Sensitivity studies show that our ignorance of the kinetics and mechanism of mercury oxidation create enormous uncertainties in the geographic distribution of mercury deposition. ${ }^{5}$ This ignorance also creates large uncertainties in the atmospheric lifetime of mercury, which hinders efforts to understand its transport and cycling between the atmosphere, hydrosphere, lithosphere, and biosphere. ${ }^{5}$

Recent field and modeling studies have focused on the role of atomic bromine (Br) in initiating $\operatorname{Hg}(0)$ oxidation in the atmosphere. ${ }^{6,7}$ This process is initiated by the reaction: ${ }^{8,9}$

$$
\mathrm{Br}+\mathrm{Hg}+\mathrm{M} \rightarrow \mathrm{BrHg} \bullet+\mathrm{M}
$$

where $\mathrm{M}$ is a third body. Unfortunately, the subsequent chemistry has scarcely been studied. Goodsite et al considered the reaction of $\mathrm{BrHg} \bullet$ with $\mathrm{OH}$ and $\mathrm{Br}$, finding both $\mathrm{HgBr}_{2}$ and $\mathrm{BrHgOH}$ to be stable gas-phase compounds. ${ }^{8}$ They also estimated the rate constant for $\mathrm{HgBr}_{2}$ formation:

$$
\mathrm{BrHg} \bullet+\mathrm{Br} \rightarrow \mathrm{HgBr}_{2}
$$


at 1 atmosphere total pressure, while Balabanov et al. computed the rate constants for various product channels of the BrHg $\bullet+\mathrm{Br}$ reaction. ${ }^{10}$ The rate constant of reaction (2) is about $1 / 10^{\text {th }}$ of the collision limit, due to the fact that the reaction is the barrierless addition of two radicals. ${ }^{8} 10$ Atmospheric models can account for the global oxidation of mercury while invoking reaction (1) as the sole process as initiating $\operatorname{Hg}(0)$ oxidation. ${ }^{11,12}$ Theoretical work in our group suggested the existence of other barrierless addition pathways, namely the reaction of $\mathrm{BrHg} \cdot$ with a variety of atmospherically abundant radicals, $\mathrm{Y}\left(\mathrm{Y}=\mathrm{NO}_{2}, \mathrm{HOO}, \mathrm{ClO}, \mathrm{BrO}\right.$, and $\left.\mathrm{IO}\right) \cdot{ }^{13,14}$ This suggestion has been widely accepted, but the reaction of $\mathrm{BrHg} \bullet$ with other atmospheric trace gases, such as volatile organic compounds (VOCs), has yet to be considered.

This paper considers two classes of reactions, starting with hydrogen abstraction from VOCs:

$$
\mathrm{BrHg} \bullet+\mathrm{RH} \rightarrow \mathrm{BrHgH}+\mathrm{R} \bullet
$$

We present results for the dissociation energy of the $\mathrm{BrHg}-\mathrm{H}$ bond that clearly indicate that $\mathrm{BrHg} \bullet$ cannot abstract hydrogen atoms from VOCs at atmospheric temperatures. The second class of reactions is addition of the $\mathrm{BrHg} \cdot$ radical to $\mathrm{sp}^{2}$-hybridized carbon atoms, using ethylene and benzene as models for the classes of olefinic and aromatic hydrocarbons:

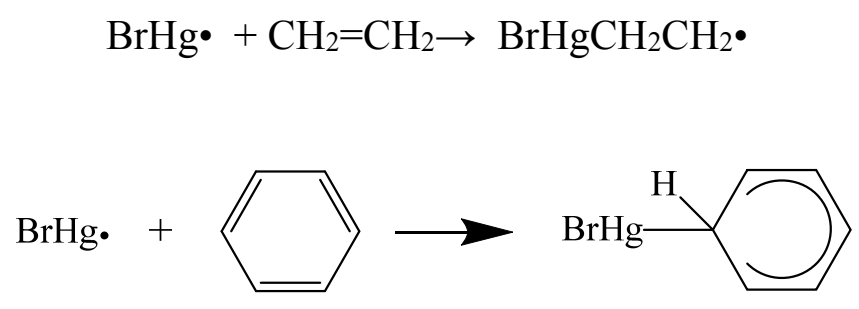

We find that the BrHg-C bond energy is so weak as to prevent the addition of BrHg $\bullet$ to aromatic hydrocarbons and limit the importance of $\mathrm{BrHg} \bullet$ addition to alkenes. 


\section{Computational Methods}

Calculations were carried out using Revision D01 of the Gaussian09 program. ${ }^{15}$ The small-core Stuttgart/Cologne scalar relativistic pseudopotentials for $\mathrm{Br}$ (10 electrons) and $\mathrm{Hg}$ (60 electrons) were used in conjunction with the corresponding aug-cc-pVTZ basis sets for the electrons treated explicitly. ${ }^{16,17,18}$ The standard Dunning correlation consistent basis sets aug-cc-pVTZ were used for hydrogen and carbon atoms. ${ }^{19,20}$ This combination of basis sets is referred to here as AVTZ. Radicals were treated with the spin-unrestricted formalism. Structures and harmonic vibrational frequencies of reactants, products, and transition states (more commonly, but inaccurately, called transition states) were determined with the $\mathrm{PBE} 0^{21}$ and $\mathrm{M} 06-2 \mathrm{X}^{22}$ functionals, both of which demonstrated very good performance for the structures, vibrational frequencies, and thermodynamics of other mercury compounds when used with the AVTZ basis set. ${ }^{14,}{ }^{23}$ PBE0 and M06-2X calculations reported here used a pruned grid of 99 radial shells with 590 angular points per shell, which is finer than the default grid. Reactants and products were verified to be potential energy minima. The identity of transition states was checked by examining the nature of their single imaginary frequencies. Energies were refined using the coupled cluster single, double, and non-iterative triple excitations $(\operatorname{CCSD}(\mathrm{T}))$ method. ${ }^{24,25}$ For a limited set of species, geometries and vibrational frequencies were also obtained using CCSD. For the same species, $\operatorname{CCSD}(\mathrm{T})$ energies were also calculated using the corresponding AVQZ basis set. CCSD and $\operatorname{CCSD}(\mathrm{T})$ calculations used the frozen core approximation. The range of molecular orbitals to be correlated was set as the $5 \mathrm{~d}$ and $6 \mathrm{~s}$ electrons of $\mathrm{Hg}$, the $4 \mathrm{~s}$ and $4 \mathrm{p}$ electrons of $\mathrm{Br}$, the $1 \mathrm{~s}$ electrons of $\mathrm{H}$, and the $2 \mathrm{~s}$ and $2 \mathrm{p}$ electrons of $\mathrm{C}$. 
Relative energies reported herein are at $0 \mathrm{~K}$ and include zero-point energies, and so are equivalent to enthalpy changes at zero K. Gibbs Free Energy changes were computed as a function of temperature. Computations of zero-point energies and Gibbs Free Energies used the rigid rotor and harmonic oscillator approximations without any scaling of vibrational frequencies. Standard transition state theory was used to compute rate constants for reaction (4) as a function of temperature, $T$, via:

$$
k_{T S T}(T)=L \frac{k_{\mathrm{B}} T}{h} \exp \left(-\Delta G^{\ddagger}(T) / R T\right)
$$

where $L$ is the reaction path degeneracy, $k_{B}$ and $R$ are, respectively, Boltzmann's

constant and the gas constant, $h$ is Planck's constant, and $\Delta G^{\neq}(T)$ is the molar Gibbs free energy of activation.

\section{Results and Discussion}

We first consider the bond dissociation energy, $\mathrm{D}_{\mathrm{o}}$, of the BrHg-H bond using three work reactions. These work reactions are listed in Table 1 together with their computed enthalpies of reaction. All three reactions involve conversion of $\mathrm{BrHgH}$ into $\mathrm{HgBr}_{2}$, as $\mathrm{HgBr}_{2}$ is one of the few compounds with a $\mathrm{BrHg}$ substituent for which the $\Delta \mathrm{H}_{\mathrm{f}}{ }^{\circ}(0 \mathrm{~K})$ is known. We use the theoretical $\Delta \mathrm{H}_{\mathrm{f}}{ }^{\circ}(0 \mathrm{~K})$ value obtained by Balabanov and Peterson ${ }^{26}(-16.3 \mathrm{kcal} / \mathrm{mol})$ which is in good agreement with, but probably more reliable than, the experimental value $(-16.1 \pm 2.0 \mathrm{kcal} / \mathrm{mol}) .{ }^{27}$ Fortunately, experiment provides very precise knowledge $( \pm 0.04 \mathrm{kcal} / \mathrm{mol})$ of $\mathrm{D}_{\mathrm{o}}$ for $\cdot \mathrm{HgH},{ }^{28}$ and reasonable precision $( \pm 0.6 \mathrm{kcal} / \mathrm{mol})$ for $\mathrm{D}_{\mathrm{o}}$ of $\mathrm{BrHg} \cdot{ }^{29}$ Values of $\Delta \mathrm{H}_{\mathrm{f}}{ }^{\circ}(0 \mathrm{~K})$ for all species

in Table 1 are listed in the Supplementary Material. ${ }^{30,31}$ Note that all uncertainties quantified here refer to $95 \%$ confidence intervals $(95 \% \mathrm{CI})$. 
Table 2 lists the values of $\Delta \mathrm{Hf}^{\circ}(0 \mathrm{~K})$ and $\mathrm{D}_{\mathrm{o}}$ for $\mathrm{BrHg}-\mathrm{H}$ implied by the three work reactions. Work reactions $\mathrm{B}$ and $\mathrm{C}$ agree well with each other for the implied value of $\mathrm{D}_{0}$ and exhibit much smaller variability in $\mathrm{D}_{0}$ across theoretical methods than work reaction $\mathrm{A}$. In addition, the value of $\mathrm{D}_{0}$ obtained in work reaction $\mathrm{C}$ is converged with respect to basis set at the $\operatorname{CCSD}(\mathrm{T})$ level. As a result, we favor the values of 73.0-73.5 kcal/mol obtained by work reactions B and $\mathrm{C}$. We estimate a $95 \%$ confidence interval $(\mathrm{CI})$ in $\mathrm{D}_{0}$ due to errors in the quantum calculations of \pm 3 $\mathrm{kcal} / \mathrm{mol}$. Uncertainties in the literature values of $\Delta \mathrm{H}_{\mathrm{f}}{ }^{\circ}(0 \mathrm{~K})$ for $\mathrm{BrHgBr}$ (see Table S2) are estimated to contribute $1 \mathrm{kcal} / \mathrm{mol}$ to the $95 \% \mathrm{CI}$. The resulting value of $\mathrm{D}_{0}$ is $73 \pm 3 \mathrm{kcal} / \mathrm{mol}$.

$\mathrm{C}-\mathrm{H}$ bonds in alkanes possess $\mathrm{D}_{0}$ of $\sim 100 \mathrm{kcal} / \mathrm{mol}^{30,31} \mathrm{C}-\mathrm{H}$ bond energies are larger when the carbon atom is $\mathrm{sp}^{2}$ - or sp-hybridized, as in alkenes or aromatics and alkynes, respectively. These bond energies are much higher than that of $\mathrm{BrHg}-\mathrm{H}$, so it is clear that $\mathrm{BrHg} \bullet$ will not abstract hydrogen atoms from hydrocarbons at temperatures relevant to atmospheric chemistry.

Let us consider functionalize VOCs with low $\mathrm{C}-\mathrm{H}$ bond energies. Ordinary aldehydes have much smaller C-H bond energies than alkanes, $86.7 \pm 0.2 \mathrm{kcal} / \mathrm{mol}$ for $\mathrm{CH}_{2}=\mathrm{O}$ and $87.9 \pm 0.5 \mathrm{kcal} / \mathrm{mol}$ for $\mathrm{CH}_{3} \mathrm{CH}=\mathrm{O} .{ }^{30,31}$ These bond energies imply rate constants for hydrogen abstraction by BrHg $\bullet$ that are, at the very least, seven orders of magnitude lower than the collision limit. $\alpha, \beta$ unsaturated carbonyl compounds such as glyoxal $(\mathrm{O}=\mathrm{CHCH}=\mathrm{O})$ and acrolein $\left(\mathrm{CH}_{2}=\mathrm{CHCH}=\mathrm{O}\right)$ do not possess $\mathrm{C}-\mathrm{H}$ bond energies lower than that of $\mathrm{CH}_{2}=\mathrm{O} .{ }^{32}$ The $\mathrm{CH}_{3} \mathrm{OO}-\mathrm{H}$ bond energy of $84.3 \pm 0.3 \mathrm{kcal} / \mathrm{mol}$ (smaller by $1.9 \mathrm{kcal} / \mathrm{mol}$ than that for HOO-H) ${ }^{30,}{ }^{31}$ still implies a rate constant for $\mathrm{BrHg} \bullet$ abstracting hydrogen from $\mathrm{ROOH}$ compounds that is at least 6 orders of magnitude slower than the collision limit. Note that the thermodynamic arguments above do not 
take into account any barrier above the enthalpy of reaction. As noted above, the currently expected fate of $\mathrm{BrHg} \bullet$ in the atmosphere is barrierless addition to radicals (primarily $\mathrm{NO}_{2}$ and HOO). The rate constants for these reactions are expected to be roughly $1 / 10^{\text {th }}$ of the collision limit: $5 \times 10^{-11} \mathrm{~cm}^{3}$ molecule ${ }^{-1} \mathrm{sec}^{-1} \cdot{ }^{13}, 33$ As concentrations of aldehydes and $\mathrm{ROOH}$ rarely exceed that of $\mathrm{NO}_{2}$ by even three orders of magnitude in the daytime atmosphere, we can conclude that hydrogen abstraction from VOCs by $\mathrm{BrHg}$ - will not be important to the atmospheric fate of BrHg•.

Another common reaction for atmospheric radicals is addition to $\mathrm{sp}^{2}$-hybridized carbon atoms in alkenes and aromatic compounds. To explore this possibility, we examined the addition of BrHg• to ethylene, which is the prototype for alkenes:

$$
\mathrm{BrHg} \bullet+\mathrm{CH}_{2}=\mathrm{CH}_{2} \rightarrow \mathrm{BrHgCH}_{2} \mathrm{CH}_{2} \bullet
$$

We also considered the displacement reaction:

$$
\mathrm{BrHg} \bullet+\mathrm{CH}_{2}=\mathrm{CH}_{2} \rightarrow \mathrm{H} \bullet+\mathrm{BrHgCH}=\mathrm{CH}_{2}
$$

The analogous reactions were also investigated for benzene, which is the prototype for aromatic hydrocarbons. In the case of benzene, attempts to optimize the geometry of a covalently bound $\mathrm{BrHgC}_{6} \mathrm{H}_{6}$ radical (such as shown in Eqn. 5) were unsuccessful at both PBE0/AVTZ and M062X/AVTZ; the structure fell apart to the van der Waals complex. We also tried to optimize a $\mathrm{BrHgC}_{6} \mathrm{H}_{6}$ radical with the analogous double-zeta basis set and the older LANL2DZ basis set, but were unsuccessful. We conclude that such a covalently bound structure is absolutely unstable. 
Figure 1 displays the structures of the reactants and products of reactions of $\mathrm{BrHg}$ with ethylene, as well as the structure of the transition state for reaction (7). We also find van der Waals complexes of $\mathrm{BrHg} \bullet$ with ethylene and benzene. Such complexes are often found in radical addition to double bonds. ${ }^{34,} 35$ Figure 2 depicts the structures of this van der Waals complex along with that of the closed-shell $\mathrm{BrHgC}_{6} \mathrm{H}_{5}$ molecule. The PBE0 and M06-2X structures of these species agree well except in the case of the transition state for $\mathrm{BrHgCH}_{2} \mathrm{CH}_{2} \bullet$ formation. The structure of this TS is much later (more like products) at M06-2X than at PBE0. As we shall see below, this has little effect on the predicted activation barrier.

Table 3 lists the relative energies for BrHg• reacting with ethylene and benzene. We first briefly discuss displacement reaction (8) and the analogous reaction of $\mathrm{BrHg} \bullet$ with benzene:

$$
\mathrm{BrHg} \bullet+\mathrm{C}_{6} \mathrm{H}_{6} \rightarrow \mathrm{H} \bullet+\mathrm{BrHgC}_{6} \mathrm{H}_{5}
$$

Both reactions are endothermic by roughly $40 \mathrm{kcal} / \mathrm{mol}$, and, therefore, will not occur. The strength of the $\mathrm{Hg}-\mathrm{C}$ bond in these molecules can be computed by subtracting $\Delta \mathrm{H}_{\mathrm{r}}^{\circ}$ for reactions (8) and (9) from the known values of $\mathrm{D}_{0}$ for the $\mathrm{H}-\mathrm{CH}=\mathrm{CH}_{2}$ and $\mathrm{C}_{6} \mathrm{H}_{5}-\mathrm{H}$ bonds (109.0 and 111.3 $\mathrm{kcal} / \mathrm{mol}$, respectively). ${ }^{30,31}$ The resulting strength of the $\mathrm{Hg}-\mathrm{C}$ bond is roughly $63 \mathrm{kcal} / \mathrm{mol}$ at $\operatorname{CCSD}(\mathrm{T}) / \mathrm{AVTZ}$ (stronger by $1-8 \mathrm{kcal} / \mathrm{mol}$ using DFT). The strength of the $\pi$-bond of ethylene is about $63 \mathrm{kcal} / \mathrm{mol},{ }^{36}$ implying that the addition of $\mathrm{BrHg} \bullet$ to ethylene (reaction 7) will be essentially thermoneutral.

Inspection of Table 3 confirms the extreme weakness of the $\mathrm{BrHg}-\mathrm{CH}_{2} \mathrm{CH}_{2} \bullet$ bond, as the energy of reaction (7) is only -0.3 to $-0.4 \mathrm{kcal} / \mathrm{mol}$ at $\operatorname{CCSD}(\mathrm{T})$. As a further check, we verified that these small reaction energies arise from the stable wavefunctions of the $\mathrm{BrHgCH}_{2} \mathrm{CH}_{2} \bullet$ radical. 
The two DFT methods disagree as to whether this reaction is slightly exothermic or slightly endothermic.

The potential energy profile for BrHg• addition to ethylene is shown in Figure 3. The addition of BrHg• to ethylene first forms a van der Waals complex that is bound by $2.6 \mathrm{kcal} / \mathrm{mole}$ at the $\operatorname{CCSD}(\mathrm{T}) / / \mathrm{PBE} 0$ level of theory. A transition state separates this complex from the $\mathrm{BrHgCH}_{2} \mathrm{CH}_{2} \bullet$ radical. The energy of the transition state relative to separated reactants spans the range -0.8 to $+2.6 \mathrm{kcal} / \mathrm{mol}$. The $\operatorname{CCSD}(\mathrm{T}) / / \mathrm{PBE} 0$ and $\operatorname{CCSD}(\mathrm{T}) / \mathrm{M} 06-2 \mathrm{X}$ values agree very well with each other at +0.8 and $+1.0 \mathrm{kcal} /$ mole despite the very different transition state geometries at PBE0 versus M06-2X.

Because of this difference in the predicted geometry of the TS, we re-computed the geometry using CCSD and the smaller VTZ analog of the AVTZ basis set that was used in other calculations on this system. The CCSD/VTZ geometry is intermediate between the PBE0/AVTZ and M06-2X/AVTZ geometries. The energy of the CCSD/VTZ structure at CCSD(T)/AVTZ is $+1.1 \mathrm{kcal} / \mathrm{mol}$ above reactants, which is nearly identical to the values in Table 3 . We are, therefore, confident that the variability in computed TS structure is not affecting the computed barrier height.

We computed rate constants for the formation and dissociation of $\mathrm{BrHgCH}_{2} \mathrm{CH}_{2} \bullet$ for $200 \leq \mathrm{T} \leq$ $400 \mathrm{~K}$. This temperature range spans the lowest temperatures relevant to atmospheric chemistry of mercury oxidation by $\mathrm{Br}$ and the highest temperatures at which $\mathrm{BrHg} \bullet$ might live long enough to enable kinetic studies of its bimolecular reactions. The reaction path degeneracy, $L$, is 4 for the forward reaction but 1 for the reverse reaction. The values of $k_{7}$ in Table 4 are two to three orders 
of magnitude lower than the expected values of the rate constants, cited previously, for $\mathrm{BrHg} \bullet$ reaction with $\mathrm{NO}_{2}$ and $\mathrm{HOO}$.

The values in Table 4 are only valid in the high-pressure limit. Rather than carry out an analysis of the pressure dependence of $\mathrm{k}$, we will draw conclusions from a more conceptual analysis of the elementary reactions:

$$
\begin{gathered}
\mathrm{BrHg} \bullet+\mathrm{CH}_{2}=\mathrm{CH}_{2} \leftrightarrows \mathrm{BrHgCH}_{2} \mathrm{CH}_{2} \bullet * \\
\mathrm{BrHgCH}_{2} \mathrm{CH}_{2} \bullet+\mathrm{M} \leftrightarrows \mathrm{BrHgCH}_{2} \mathrm{CH}_{2} \bullet+\mathrm{M}
\end{gathered}
$$

where $\mathrm{BrHgCH}_{2} \mathrm{CH}_{2} \bullet *$ indicates activated (internal excited) radicals. In this analysis, $\mathrm{k}_{10}$ is the high-pressure limiting value of $\mathrm{k}_{7}$. The value of $\mathrm{k}_{-7}$ listed in Table 3 is for dissociation of thermalized $\mathrm{BrHgCH}_{2} \mathrm{CH}_{2} \bullet$, so $\mathrm{k}-10$ (for dissociation of energized $\mathrm{BrHgCH}_{2} \mathrm{CH}_{2} \bullet$ ) is at least as large as k-7. The pseudo-first order rate constant for collision of $\mathrm{BrHgCH}_{2} \mathrm{CH}_{2}$ • with air molecules at $1 \mathrm{~atm}$ is $\sim 5 \times 10^{10} \mathrm{sec}^{-1}$. We can see that, at $1 \mathrm{~atm}, \mathrm{BrHgCH}_{2} \mathrm{CH}_{2} \bullet *$ will fall apart via reaction -10 at least 30 to 200 times faster than it will undergo even a single de-activating collision. As a result, reaction 7 is far from the high pressure limit at 1 atm, so its importance would seem to be much smaller than indicated by the values in Table 4 . As a result, we conclude that $\mathrm{BrHgCH}_{2} \mathrm{CH}_{2} \bullet$ will not react with ethylene in the atmosphere.

As ethylene is the prototype for alkenes, it is tempting to generalize our conclusion to larger alkenes. However, addition of $\mathrm{BrHg} \bullet$ to larger alkenes can form secondary or tertiary alkyl radicals, which are expected be more stable than a primary radical like $\mathrm{BrHgCH}_{2} \mathrm{CH}_{2} \bullet$. Also, BrHg• addition to conjugated dienes (e.g., isoprene) or $\alpha, \beta$ unsaturated carbonyls (e.g., methacrolein or methylvinylketone) could lead to resonance-stabilized radicals. The enhanced 
stability of these radicals would make their dissociation much slower than that of $\mathrm{BrHgCH}_{2} \mathrm{CH}_{2}$, potentially further reaction along the common pathways for carbon-centered radicals.

\section{Conclusions}

The BrHg-H bond energy is sufficiently weak $(\sim 73 \pm 4 \mathrm{kcal} / \mathrm{mole})$ that the $\mathrm{BrHg} \bullet$ radical cannot abstract hydrogen atoms from carbon atoms. This means that this large class of reactions common to radicals in the atmosphere is not feasible for BrHg. In addition, the BrHg-C bond is essentially as strong as the $\pi$ bond in alkenes- roughly $63 \mathrm{kcal} / \mathrm{mol}$. This means that $\mathrm{BrHg}-\mathrm{C}$ bonds formed in $\mathrm{BrHg}$ - addition to $\mathrm{C}-\mathrm{C}$ double bonds may tend to break before the resulting carbon-centered radical can undergo further reactions. As a result, BrHg• oxidation to $\mathrm{Hg}$ (II) by addition to $\mathrm{sp}^{2}$-hybridized carbon atoms might only occur to a limited extent. Further investigations of reactions of $\mathrm{BrHg} \bullet$ with $\mathrm{C}_{3}$ and larger alkenes are needed to fully assess the importance of this class of reactions for the atmospheric fate of $\mathrm{BrHg} \cdot$.

\section{Acknowledgement}

We wish to thank Yuge Jiao for advice on the calculations, and two anonymous reviewers for their helpful comments. This work used the Extreme Science and Engineering Discovery Environment (XSEDE), which is supported by National Science Foundation grant number ACI1053575; specifically, it used the Comet system at the San Diego Supercomputing Center.

\section{Supplementary Information}


Absolute energies, zero-point energies, Cartesian coordinates, and vibrational frequencies of species in the reaction of $\mathrm{BrHg} \bullet$ with ethylene and benzene; absolute energies, zero-point energies, and literature thermodynamics data for species involved in work reactions A-C. 
Version of Wednesday, July 27, 2016

\section{Figure Captions}

Figure 1. Structures of species involved in the reactions of $\mathrm{BrHg} \bullet$ with ethylene. PBE0/AVTZ and M06-2X values (in square brackets) of bond lengths are in Ångstroms with valence angles and dihedral angles in degrees.

Figure 2. Structure of the van der Waals complex of BrHg• with benzene (two top views) and structure of the $\mathrm{BrHgC}_{6} \mathrm{H}_{5}$ molecule. PBE0/AVTZ and M06-2X values (in square brackets) of bond lengths are in Ångstroms with valence angles and dihedral angles in degrees. The C-C bond length in benzene is given for comparison.

Figure 3. Potential energy profile for addition of $\mathrm{BrHg} \bullet$ to ethylene $(\mathrm{kcal} / \mathrm{mol}$ at $0 \mathrm{~K}$, including zeropoint energy) using the AVTZ basis set. Thick lines illustrate the $\operatorname{CCSD}(\mathrm{T})$ relative energies computed with geometries and zero-point energies from PBE0. The thinner lines show the profile at PBE0 (with energies in italics), and the M06-2X energies are listed in square brackets. 


\section{REFERENCES}

[1] W. H. Schroeder, J. Munthe, Atmos. Env. 32 (1998) 809.

[2] C. J. Lin, S. O. Pekhonen, Atmos. Env. 33 (1999) 2067.

[3] P. A. Ariya, M. Amyot, A. Dastoor, D. Deeds, A. Feinberg, G. Kos, A. Poulain, A. Ryjkov, K. Semeniuk, M. Subir, K. Toyota, Chem. Rev. 115 (2105) 3760.

[4] S. Onishi, S. H. Jo, K. Shoda, P. D. Jo, S. Kato, SAE paper 790501; 1979.

[5] C. Lin, P. Pongprueksa, O. R. Bullock, Jr. S. E. Lindberg, S. O. Pehkonen, C. Jang, T. Braverman, T. C. Ho, Atmos. Environ. 41 (2007) 6544.

[6] S. Wang, J. A. Schmidt, S. Baidara, S. Coburna, B. Dix, T. K. Koenig, E. Apel, D. Bowdalo, T. L. Campos, E. Eloranta, M. J. Evans, J. P. DiGangi, M. A. Zondloh, R.-S. Gao, J. A. Haggerty, S. R. Hall, R. S. Hornbrook, D. Jacob, B.Morley, B. Pierce, M. Reeves, P. Romashkin, A. ter Schure, R. Volkamer, Proc. Nat. Acad. Sci. 112 (2015) 9281.

[7] K. D. Custard, C. R. Thompsonb, K. A. Pratt, P B. Shepson, J. Liao, L. G. Huey, J. J. Orlando, A. J. Weinheimer, E. Apel, S. R. Hall, F. Flocke, L. Mauldina, R. S. Hornbrook, D. Pöhler, S. General, J. Zielcke, W. R. Simpson, U. Platt, A. Fried, P. Weibring, B. C. Sive, K. Ullmann, C. Cantrell, D. J. Knapp, and D. D. Montzka, Atmos. Chem. Phys. 15 (2015) 10799.

[8] M. E. Goodsite, J. M. C. Plane, and H. Skov, Environ. Sci. Technol. 38 (2004) 1772.

[9] B. C. Shepler, N. B. Balabanov, K. A. Peterson, J. Chem. Phys. 127 (2007) 164304.

[10] N. B. Balabanov, B. C. Shepler, K. A Peterson, J. Phys. Chem. A 109 (2005) 8765.

[11] C. D. Holmes, D. Jacob, E. S. Corbitt, J. Mao, X. Yang, R. Talbot, F. Slemr, Atmos. Chem. Phys. 10 (2010) 12037. 
[12] F. De Simone, C. N. Gencarelli, I. M. Hedgecock, N. Pirrone, Environ. Sci. Technol. 50 (2016) 5154.

[13] T. S. Dibble, M. J. Zelie,H. Mao, Atmos. Chem. Phys. 12 (2012) 10271.

[14] Y. Jiao, T. S. Dibble, J. Phys. Chem. A 119 (2015) 10502.

[15] Gaussian 09, Revision D.01, M. J. Frisch, G. W. Trucks, H. B. Schlegel, G. E. Scuseria, M. A. Robb, J. R. Cheeseman, G. Scalmani, V. Barone, B. Mennucci, G. A. Petersson, H. Nakatsuji, M. Caricato, X. Li, H. P. Hratchian, A. F. Izmaylov, J. Bloino, G. Zheng, J. L. Sonnenberg, M. Hada, M. Ehara, K. Toyota, R. Fukuda, J. Hasegawa, M. Ishida, T. Nakajima, Y. Honda, O. Kitao, H. Nakai, T. Vreven, J. A. Montgomery, Jr. J. E. Peralta, F. Ogliaro, M. Bearpark, J. J. Heyd, E. Brothers, K. N. Kudin, V. N. Staroverov, T. Keith, R. Kobayashi, J. Normand, K. Raghavachari, A. Rendell, J. C. Burant, S. S. Iyengar, J. Tomasi, M. Cossi, N. Rega, J. M. Millam, M. Klene, J. E. Knox, J. B. Cross, V. Bakken, C. Adamo, J. Jaramillo, R. Gomperts, R. E. Stratmann, O. Yazyev, A. J. Austin, R. Cammi, C. Pomelli, J. W. Ochterski, R. L. Martin, K. Morokuma, V. G. Zakrzewski, G. A. Voth, P. Salvador, J. J. Dannenberg, S. Dapprich, A. D. Daniels, O. Farkas, J. B. Foresman, J. V. Ortiz, J. Cioslowski, D. J. Fox, Gaussian, Inc. Wallingford CT, 2013.

[16] K. A. Peterson, C. Puzzarini, Theor. Chem. Acc. 114 (2005) 283.

[17] K.A. Peterson, B.C. Shepler, D. Figgen, H Stoll, J. Phys. Chem. A 110 (2006) 13877.

[18] D. Figgen, G. Rauhut, M. Dolg, H. Stoll, Chem. Phys. 311(2005) 227.

[19] T. H. Dunning Jr., J. Chem. Phys. 90 (1989) 1007.

[20] R. A. Kendall, T. H. Dunning Jr., R. J. Harrison, J. Chem. Phys. 96 (1992) 6796.

[21] C. Adamo, V. Barone, J. Chem. Phys. 110 (1999) 6158. 
[22] Y. Zhao, D. G. Truhlar, Theor. Chem. Acc. 120 (2007) 215.

[23] M. M. Montero-Campillo, A. M. Lamsabhi, O. Mó, M. Yáñez, Theor. Chem. Acc. 132 (2013) 1328.

[24] G. E. Scuseria, C. L. Janssen, H. D. Schaefer, J. Chem. Phys. 89 (1988) 7382.

[25] K. Raghavachari, G. W. Trucks, J. A. Pople, M. Head-Gordon, Chem. Phys. Lett. 157 (1989) 479.

[26] N. B Balabanov, K. A. Peterson, J. Phys. Chem. A 107 (2003) 7465.

[27] M. W. Chase, Jr., C. A. Davies, J. R. Downey, Jr., D. J. Frurip, R. A. McDonald, A. N. Syverud, J. Phys. Chem. Ref. Data 14, 1985, Suppl. No. 1

[28] W. C. Stwalley, J. Chem. Phys. 63 (1975) 3062.

[29] J. Tellinghuisen, J. G. Ashmore, Chem. Phys. Lett. 102 (1983) 10.

[30] B. Ruscic, R. E. Pinzon, M. L. Morton, G. von Laszewski, S. Bittner, S. G. Nijsure, K. A. Amin, M. Minkoff, A. F. Wagner, J. Phys. Chem. A 108 (2004) 9979.

[31] B. Ruscic, Active Thermochemical Tables (ATcT) values based on ver. 1.118 of the Thermochemical Network (2015); available at ATcT.anl.gov. Last downloaded June 17, 2016.

[32] C. F. Goldsmith, G. R. Magoon, W. H. Green, J. Phys. Chem. A, 116 (2012) 9033.

[33] F. Wang, A. Saiz-Lopez, A. S. Mahajan, J. C. Gómez Martín, D. Armstrong, M. Lemes, T. Hay, C. Prados-Roman, Atmos. Chem. Phys. $14 \quad$ (2014) 1323. http://jpldataeval.jpl.nasa.gov/

[34] E. E. Greenwald, S. W. North, Y. Georgievskii, S. J. Klippenstein, J. Phys. Chem. A 109 (2005) 6031. 
Version of Wednesday, July 27, 2016

[35] I. W. M. Smith, A. M. Sage, N. M. Donahue, E. Herbst, D. Quan, Faraday Discuss. 133 (2006) 137.

[36] S. I. Miller, J. Chem. Ed. 55 (1978) 778. 
Graphical Abstract

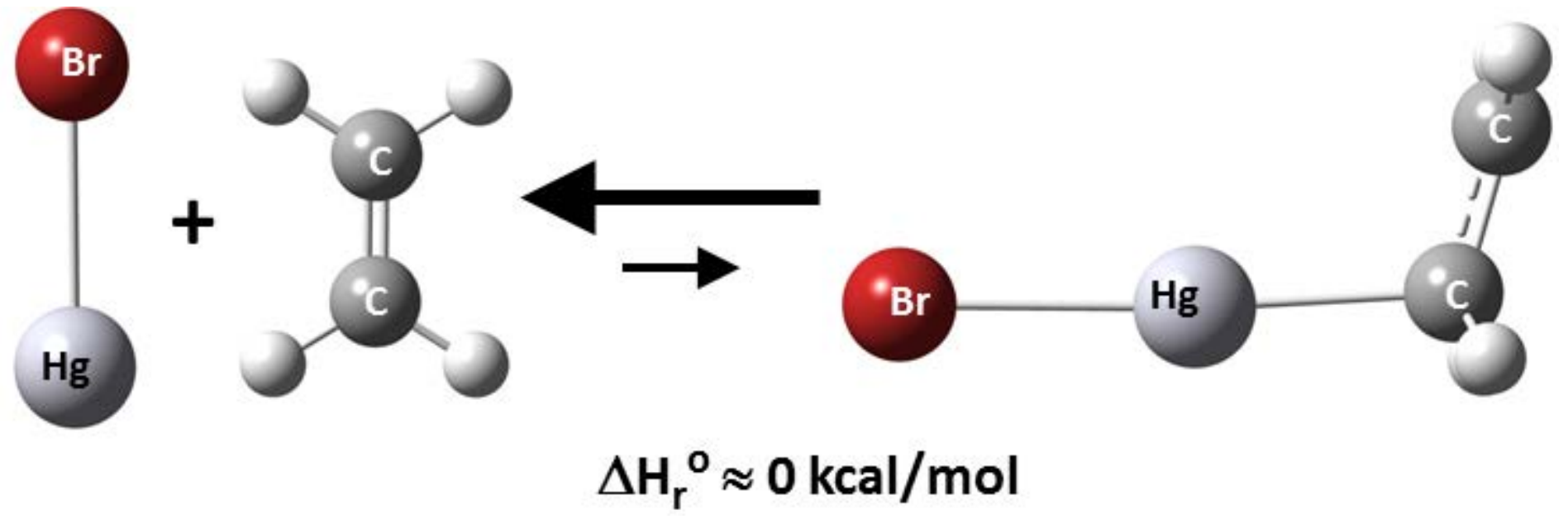


Table 1. Enthalpies of work reactions ( $\mathrm{kcal} / \mathrm{mol}$ at $0 \mathrm{~K}$, including zero-point energy) used to determine $\Delta \mathrm{H}_{\mathrm{f}}{ }^{\circ}(0 \mathrm{~K})$ for $(\mathrm{BrHgH})$ and $\mathrm{D}_{0}$ for $\mathrm{BrHg}-\mathrm{H}$. The AVTZ basis set was used throughout, except where noted. $\operatorname{CCSD}(\mathrm{T})$ results use geometries and zero-point energies calculated at CCSD.

\begin{tabular}{|l|c|c|c|c|}
\hline Work Reaction & M06-2X & PBE0 & CCSD & $\begin{array}{c}\text { CCSD(T)// } \\
\text { CCSD }\end{array}$ \\
\hline $\mathrm{A}) \mathrm{BrHgH}+\mathrm{CH}_{3} \mathrm{Br} \rightarrow \mathrm{BrHgBr}+\mathrm{CH}_{4}$ & -34.2 & -33.1 & -29.3 & -28.6 \\
\hline $\mathrm{B}) \mathrm{BrHgH}+\mathrm{HBr} \rightarrow \mathrm{BrHgBr}+\mathrm{H}_{2}$ & -17.7 & -14.6 & -13.6 & -15.1 \\
\hline $\mathrm{C}) \mathrm{BrHgH}+\mathrm{BrHg} \bullet \rightarrow \mathrm{BrHgBr}+\cdot \mathrm{HgH}$ & 9.8 & 8.6 & 8.3 & $8.1(8.1)^{\mathrm{a}}$ \\
\hline
\end{tabular}

a) Value in parentheses from $\mathrm{CCSD}(\mathrm{T}) / \mathrm{AVQZ}$ energies. 
Table 2. $\Delta \mathrm{H}_{\mathrm{f}}{ }^{\circ}$ for $\mathrm{BrHgH}$ and $\mathrm{D}_{0}$ for $\mathrm{BrHg}-\mathrm{H}(\mathrm{kcal} / \mathrm{mol}$ at $0 \mathrm{~K})$ from various levels of theory using the AVTZ basis set, except where specified. $\operatorname{CCSD}(\mathrm{T})$ results use geometries and zeropoint energies calculated at CCSD.

\begin{tabular}{|l|c|c|c|c|c|}
\hline Work Reaction & M06-2X & PBE0 & CCSD & CCSD(T) & CCSD(T)/AVQZ \\
\hline & \multicolumn{5}{|c|}{} \\
\hline $\mathrm{A}) \mathrm{BrHgH}+\mathrm{CH}_{3} \mathrm{Br} \rightarrow \mathrm{BrHgBr}+\mathrm{CH}_{4}$ & 7.0 & 5.9 & 1.8 & 1.4 & -- \\
\hline $\mathrm{B}) \mathrm{BrHgH}+\mathrm{HBr} \rightarrow \mathrm{BrHgBr}+\mathrm{H}_{2}$ & 8.1 & 5.0 & 5.0 & 5.5 & -- \\
\hline $\mathrm{C}) \mathrm{BrHgH}+\mathrm{BrHg} \bullet \rightarrow \mathrm{BrHgBr}+\cdot \mathrm{HgH}_{\mathrm{f}}{ }^{\circ}$ & 4.2 & 5.5 & 5.7 & 5.9 & 5.9 \\
\hline \\
\hline $\mathrm{A}) \mathrm{BrHgH}+\mathrm{CH}_{3} \mathrm{Br} \rightarrow \mathrm{BrHgBr}+\mathrm{CH}_{4}$ & 72.0 & 73.1 & 77.2 & 77.6 & -- \\
\hline $\mathrm{B}) \mathrm{BrHgH}+\mathrm{HBr} \rightarrow \mathrm{BrHgBr}+\mathrm{H}_{2}$ & 70.9 & 74.0 & 74.0 & 73.5 & -- \\
\hline $\mathrm{C}) \mathrm{BrHgH}+\mathrm{BrHg} \bullet \rightarrow \mathrm{BrHgBr}+\cdot \mathrm{HgH}$ & 74.8 & 73.5 & 73.2 & 73.0 & 73.0 \\
\hline
\end{tabular}


Table 3. Relative energies for reactions of $\mathrm{BrHg} \bullet$ with ethylene and benzene $(\mathrm{kcal} / \mathrm{mol}$ at $0 \mathrm{~K}$, including zero-point energy) using the AVTZ basis set.

\begin{tabular}{|l|c|c|c|c|}
\hline Reaction & PBE0 & M06-2X & $\begin{array}{c}\text { CCSD(T)// } \\
\text { PBE0 }\end{array}$ & $\begin{array}{c}\text { CCSD(T)// } \\
\text { M06-2X }\end{array}$ \\
\hline $\mathrm{BrHg} \bullet+\mathrm{CH}_{2}=\mathrm{CH}_{2} \rightarrow \mathrm{BrHg} \bullet---\mathrm{CH}_{2}=\mathrm{CH}_{2}$ & -1.5 & -3.5 & -2.6 & -- \\
\hline $\mathrm{BrHg} \bullet+\mathrm{CH}_{2}=\mathrm{CH}_{2} \rightarrow \mathrm{BrHgCH}_{2} \mathrm{CH}_{2} \bullet$ & -4.3 & 2.6 & -0.4 & -0.3 \\
\hline $\mathrm{TS}\left[\mathrm{BrHg} \bullet+\mathrm{CH}_{2}=\mathrm{CH}_{2} \rightarrow \mathrm{BrHgCH}_{2} \mathrm{CH}_{2} \bullet\right]$ & -0.8 & 2.8 & 0.8 & 1.0 \\
\hline $\mathrm{BrHg} \bullet+\mathrm{CH}_{2}=\mathrm{CH}_{2} \rightarrow \mathrm{H} \bullet+\mathrm{BrHgCH}^{-} \mathrm{CH}_{2}$ & 38.0 & 42.7 & 45.8 & -- \\
\hline $\mathrm{BrHg} \bullet+\mathrm{C}_{6} \mathrm{H}_{6} \rightarrow \mathrm{BrHg} \bullet--\mathrm{C}_{6} \mathrm{H}_{6}$ & -2.2 & -6.9 & -- & -- \\
\hline $\mathrm{BrHg} \bullet+\mathrm{C}_{6} \mathrm{H}_{6} \rightarrow \mathrm{H} \bullet+\mathrm{BrHgC}_{6} \mathrm{H}_{5}$ & 38.7 & 43.0 & -- & -- \\
\hline
\end{tabular}


Table 4. Rate constants in the high-pressure limit for the reactions (7) and (-7) at CCSD(T)//PBE0/AVTZ.

\begin{tabular}{|c|c|c|}
\hline Temperature (K) & $\mathrm{k}_{7}\left(\mathrm{~cm}^{3}\right.$ molecule $\left.^{-1} \sec ^{-1}\right)$ & $k_{-7}\left(\sec ^{-1}\right)$ \\
\hline 200 & $2.1 \times 10^{-13}$ & $1.5 \times 10^{12}$ \\
\hline 250 & $4.0 \times 10^{-13}$ & $3.3 \times 10^{12}$ \\
\hline 285 & $5.7 \times 10^{-13}$ & $4.9 \times 10^{12}$ \\
\hline 333 & $8.6 \times 10^{-13}$ & $7.5 \times 10^{12}$ \\
\hline 350 & $9.8 \times 10^{-13}$ & $8.4 \times 10^{12}$ \\
\hline 400 & $1.4 \times 10^{-12}$ & $1.1 \times 10^{13}$ \\
\hline
\end{tabular}



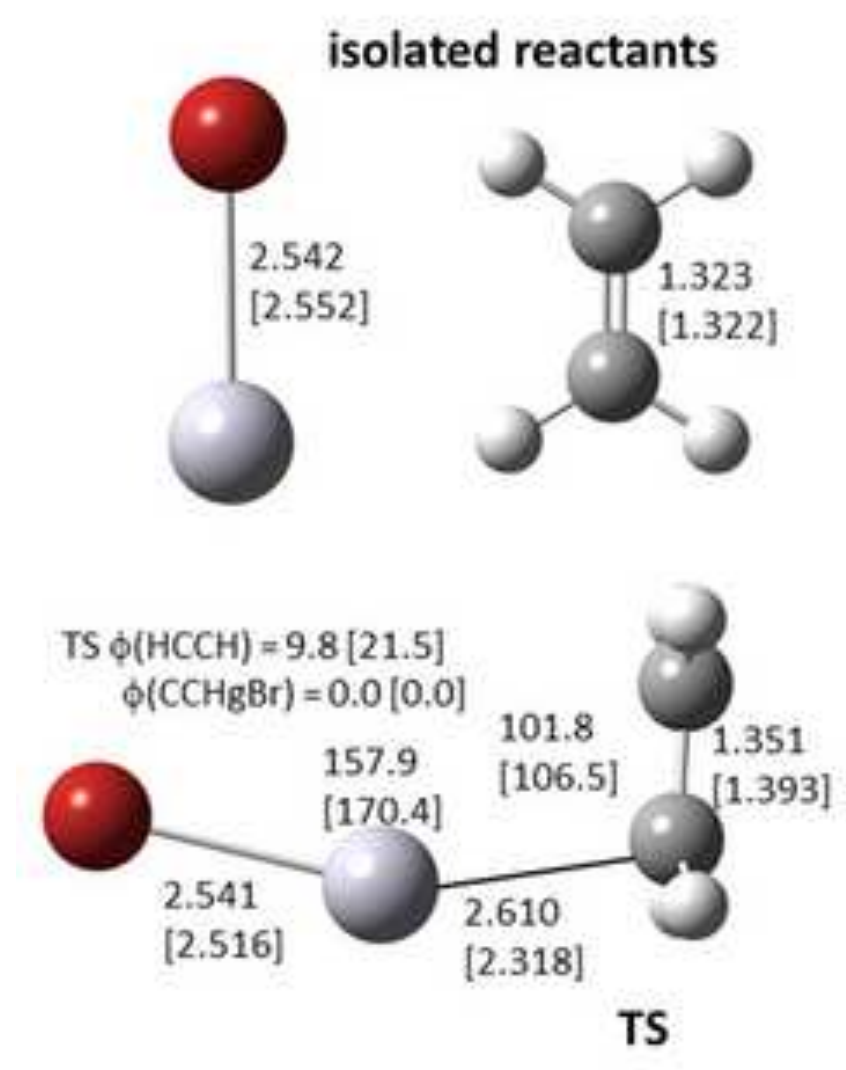

$\mathrm{BrHgCH}_{2} \mathrm{CH}_{2}$ radical
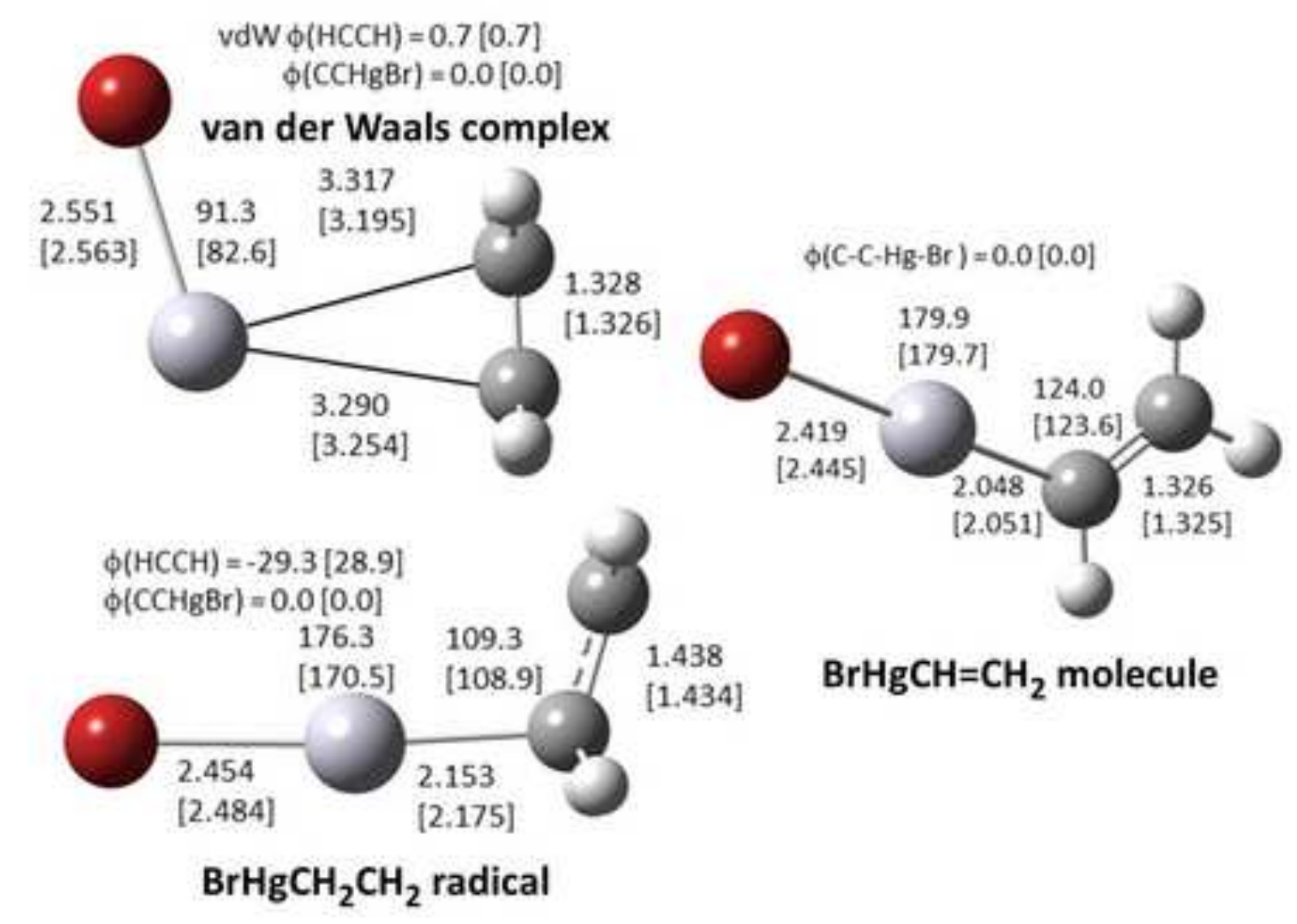

$\mathrm{BrHgCH}=\mathrm{CH}_{2}$ molecule

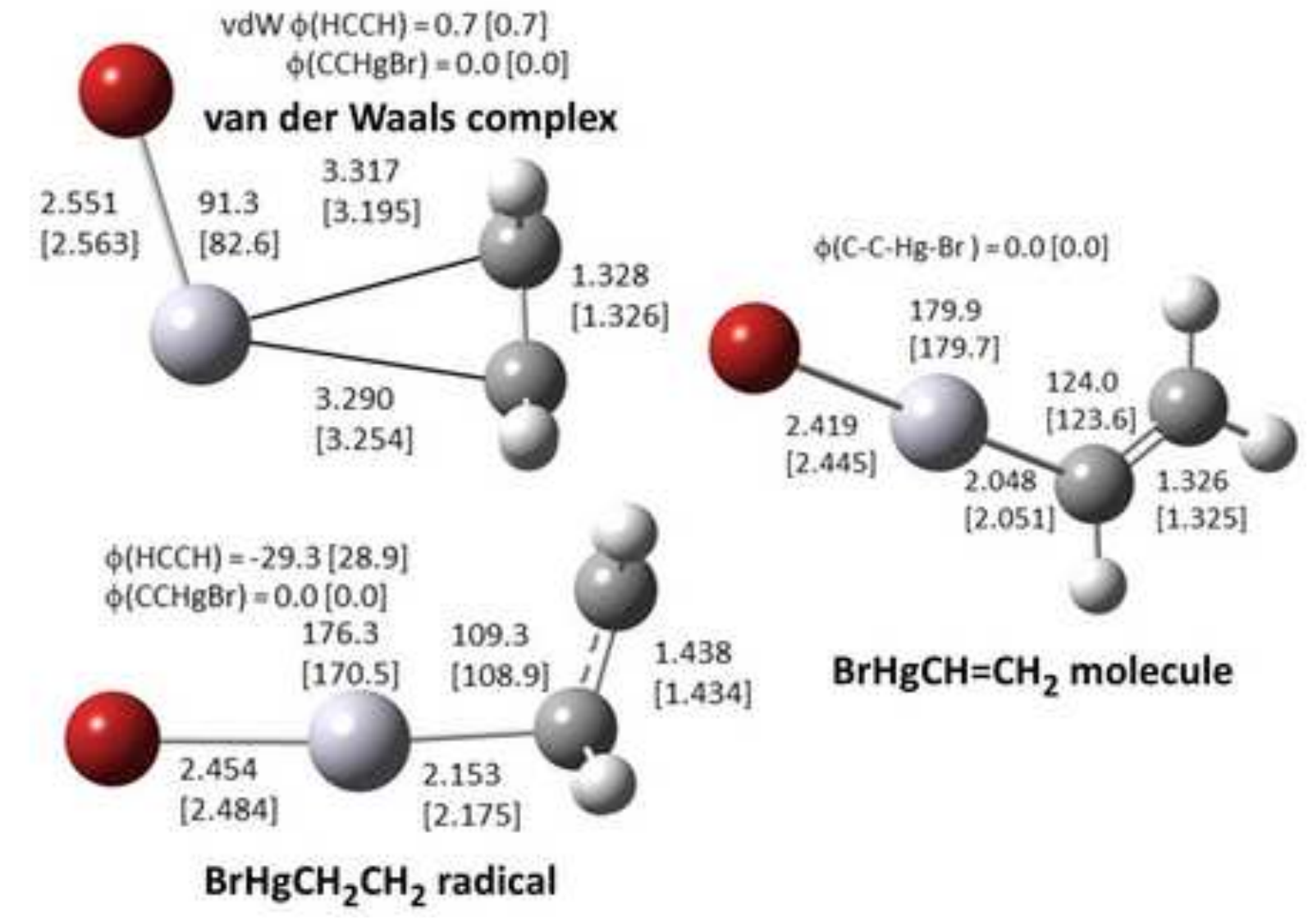




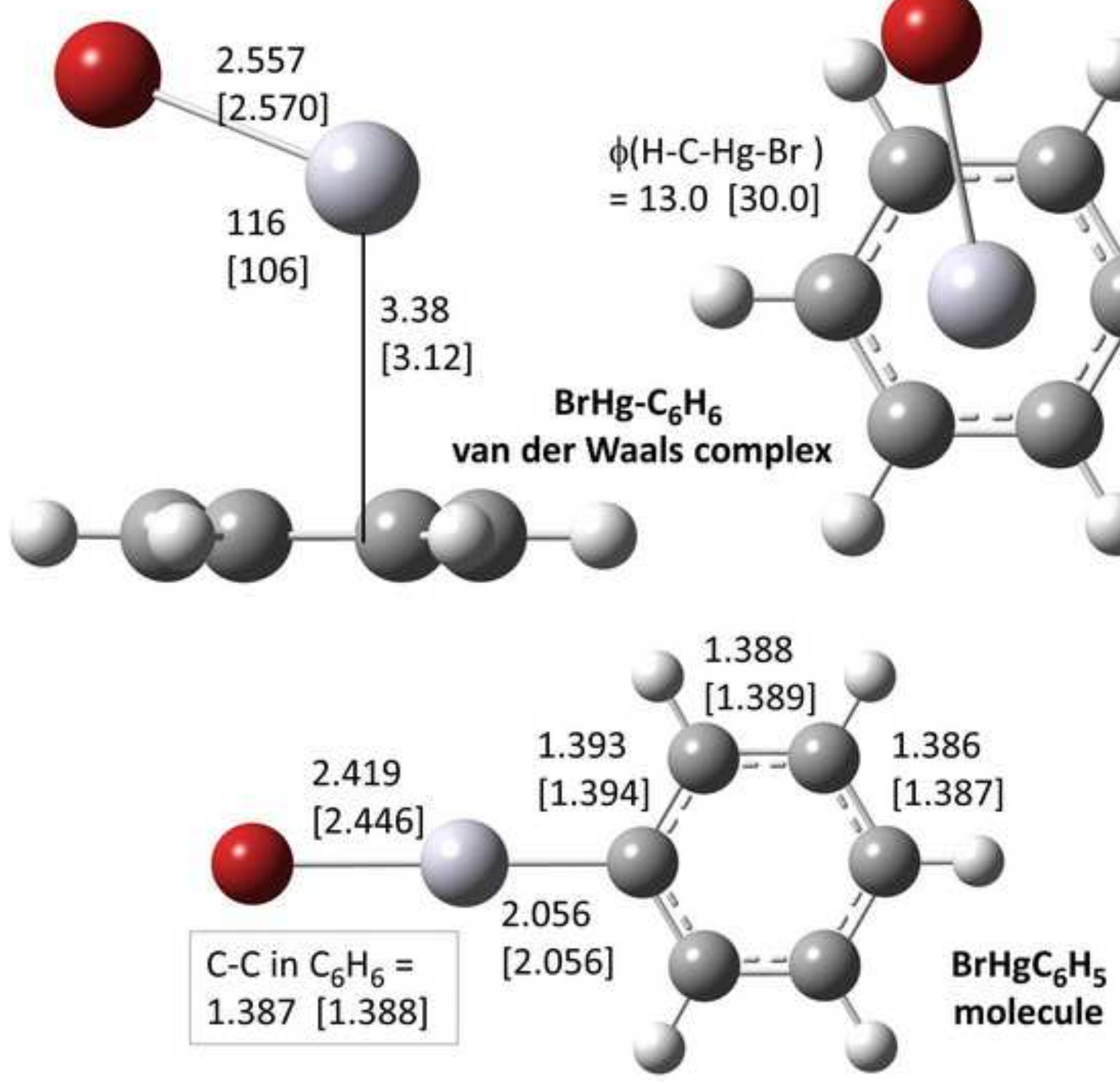




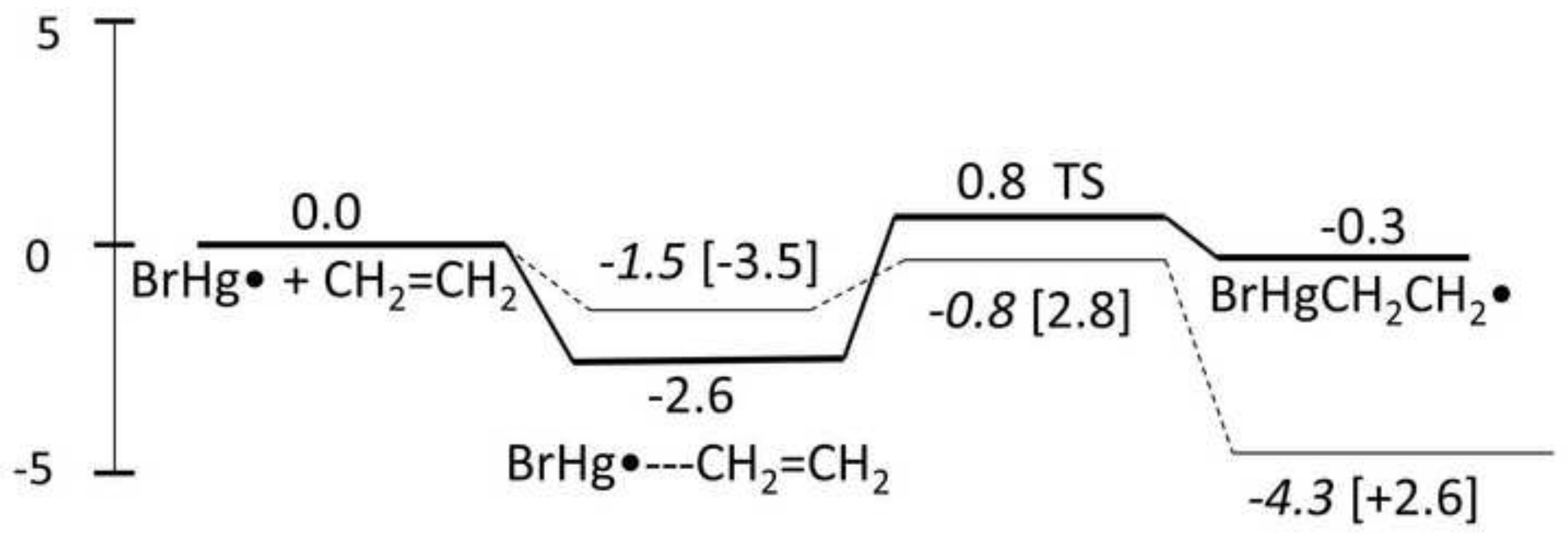

